\title{
Evaluation of the onset and length of growing season to define planting date-'a case study for Mali (West Africa)'
}

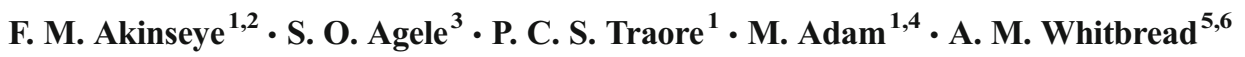

Received: 11 May 2014 / Accepted: 7 April 2015 /Published online: 28 April 2015

(C) Springer-Verlag Wien 2015

\begin{abstract}
The agroecological zones (AEZ) of Mali fall within the semi-arid climate, the ability to determine efficiently or predict accurately the onset of growing season (OGS), and length of growing season (LGS) cannot be over-emphasized due to highly variable rainfall pattern and the dependence of smallholder farmers practising on rainfed farming agriculture. In this study, we determined the most suitable method for predicting the onset date of rainfall across AEZ that fitted with the planting windows of major cereal crops (maize, millet, and sorghum). Using long-term daily rainfall records from 22 meteorological stations spread across AEZ of Mali, four (4) known methods were applied to determine the onset dates of the rain. The mean onset dates were statistically compared with the farmer's planting window for the selected weather stations to determine the suitable dates of OGS and LGS. The hypothesis considered a time lag minimum of 7 days between the mean onset date and traditional farmer sowing dates for the crops. Then, the preferred method was used to
\end{abstract}

F. M. Akinseye

F.Akinseye@cgiar.org

1 International Crops Research Institute for the Semi-arid Tropics (ICRISAT), BP320, Bamako, Mali

2 Department of Meteorology, Federal University of Technology, PMB 704, Akure, Ondo State, Nigeria

3 Department of Crop, Soil and Pest Management, Federal University of Technology, PMB 704, Akure, Ondo State, Nigeria

4 CIRAD- UMR AGAP, Avenue Agropolis, 34398 Montpellier Cedex 5, France

5 Crop Production Systems in the Tropics, Georg-August-Universität Göttingen, Grisebachstraße 6, 37077 Göttingen, Germany

6 International Crops Research Institute for the Semi-arid Tropics (ICRISAT), Patancheru 502324, Andhra Pradesh, India estimate OGS based on early, normal and late dates respectively across the stations. Also, the estimated LGS according to each zone was evaluated using probability distribution chart with duration to maturity for varieties of the same crops. The results showed that Def_4 was found appropriate for Sahelian and Sudano-Sahelian zones; Def_3 satisfied the criteria and exhibited superior capacity into farmer's average planting date over Sudanian and Guinea Savannah zones. These results have an important application in cropping systems in order to prevent crop failure and ensure a better choice of crop variety according to LGS under climate variability and change being experienced across Mali.

\section{Introduction}

The semi-arid tropics are characterized by mostly rainfed agriculture, with a highly variable rainfall (amount and distribution) and time of onset of the rains (Graef and Haigis 2001). Mali is located in West Africa semi-arid climate (latitudes of $10^{\circ}$ to $25^{\circ} \mathrm{N}$ ), straddling the sub-tropical band called the Sahel. The northern parts of Mali reach well into the dry Sahara desert, while the southern regions experience a wetter and more tropical climate. Rainfed agriculture is the dominant source of food production accounting for nearly $90 \%$ of staple cropland area (Rosegrant et al. 2002), and despite a wealth of agronomic and crop improvement research efforts from the 1970s, food insecurity is still widespread.

High spatial and temporal variability of rainfall, reflected by dry spells within the growing season and recurrent droughts and floods, have been considered the most important factors affecting agricultural productivity in the region. The intra-seasonal and inter-annual variability of rainfall is often given as the main reason for crop failure and food shortages (e.g. Sivakumar 1988; Usman et al. 2005; Sultan et al. 2005; 
Mishra et al. 2008). Reports have shown that planting too early might lead to crop failure, and in turn, planting too late might reduce valuable growing time and crop yields. However, there is still no consensus answer in the literature about the question of how much rain and over which period defines the onset of rainy season (ORS) for agroclimatological impact studies. The definition of Stern et al. (1981), hereinafter referred to as the Stern definition, is possibly the most widespread rainfall-based definition used to estimate local ORS dates. This approach states that the wet season has started when, for the first time after March 1st, $25 \mathrm{~mm}$ of rain falls within two consecutive days and no dry period of ten or more days occurs in the following 30 days. Prior to its application, however, the user must adapt these criteria, which strongly depend on local weather conditions, soil types, the evaporative demands of crops, cropping practices, etc. Adequate estimation of the onset of growing season (OGS) for planting to commence is critical in West African smallholder systems due to (i) the large variability and uncertainty in onset dates of the rainy season, (ii) highly variable labour constraints within communities affecting effective sowing dates, and (iii) indirect reliance on specific adaptation traits such as photoperiod sensitivity and other evasive mechanisms, and these factors have significant impact on crop biomass and grain yield outcomes. As stated by Laux et al. (2008), prolonged dry spells of two or more weeks soon after sowing are usually disastrous for plant production, leading to poor germination, uneven plant spacing resulting in yield reductions or total crop failure. For successful cultivating crops, it is important to know whether (i) the rains are continuous and sufficient to ensure adequate soil moisture during planting time and (ii) if this level would be maintained or even increased during the growing period to avoid crop failure (Walter 1967). Thus, reliable estimates/ predictions of the onset date and length of growing season has proved as one of the ways to prevent or reduce the risk of annual crop failure. It therefore become imperative that the most important variable - the onset of the rainy season, which coincides with the start of the growing season, is predicted ahead, i.e. for the ongoing or forthcoming season, on the basis of reliable scientific methods (Ati et al. 2002). Knowledge of the onset, of cessation and, thus, of the length of the growing season significantly supports the timely preparation of farmland, mobilization of seed/crop, manpower and equipment, and also reduces the risk of planting and sowing too late or too early (Omotosho et al. 2000).

Several studies have adopted different definitions for the onset and end of the rainy season (Stern and Coe 1982; Sivakumar 1988; Diallo 2001; Ati et al. 2002; Odekunle 2004; Kasei and Afuakwa 1991). These methods were used by different researchers and for different purposes across West African countries. According to literature, rainfall data remain widely used among scientists to depict the onset and cessation of growing season mainly because they are more readily available and constitute a more direct approach rather than the use of some other factor (e.g. temperature and evapotranspiration) from which to make inference. The onset of growing period (OGP) was determined in the Volta basin region by Laux et al. (2008) that applied a fuzzy logic approach based on the definition of Stern et al. (1981) that does not yield an onset date for every year, due to the inflexibility of its constraints which have to be fulfilled simultaneously. The study reported earlier onset of the wet season in the Volta basin, of 0.4-0.8 days/year, while the end of the rainy season has remained relatively fixed. Among the methods based on rainfall data, distinction can be made between absolute methods based on a set threshold value and relative methods based on a set proportion relative to the total rainfall (Odekunle 2004; Laux et al. 2008, 2009). In this study, we determined the most appropriate method suitable for each agroecological zone of Mali that match farmer planting window for major cereal crops (maize, millet and sorghum). This approach becomes important not to avoid the use of rainfall estimate alone in the prediction but rather to fill the knowledge gap between the OGS and farmer's planting time as well as the use of single method to predict onset of rain across semi-arid agroecological zones (AEZ). Thus, this study aims to compare statistically known methods for predicting the onset of the rainy season and to determine the onset of growing season and in comparison with the potential farmer's sowing windows for cereal major crop (maize, millet and sorghum) and finally to establish the most suitable onset date and length growing season for the each ecological zone.

\section{Materials and methods}

\subsection{Rainfall dataset}

Long-term daily rainfall data from 22 agroclimatology stations distributed across four (4) agroecological zones were collected from the database of the National Meteorology office, Republic du Mali (Fig. 1).We grouped the stations into agroecological zones (AEZ) based on the pattern of the intraseasonal distribution of rainfall. The selection of the stations was randomly within the ecological zone for having a complete daily record of 30 consecutive years or more (Table 1). In addition, these stations were selected because they provide appropriate spatial coverage of the different agroecological zones in Mali semi-arid areas. As depicted in Fig. 1, Sahelian annual rainfall total ranges from 250 to $500 \mathrm{~mm}$, SudanoSahelian ranges from 500 to $800 \mathrm{~mm}$, and Sudanian received annual rainfall between 800 and $1100 \mathrm{~mm}$, while Guinea Savanna received above $1100 \mathrm{~mm}$ annual rainfall. The average annual rainfall indicates decrease in rainfall northward and also accompanied by high standard deviation. The coefficient of variation $(\mathrm{CV})$ shows the lowest value in Guinean zone and 


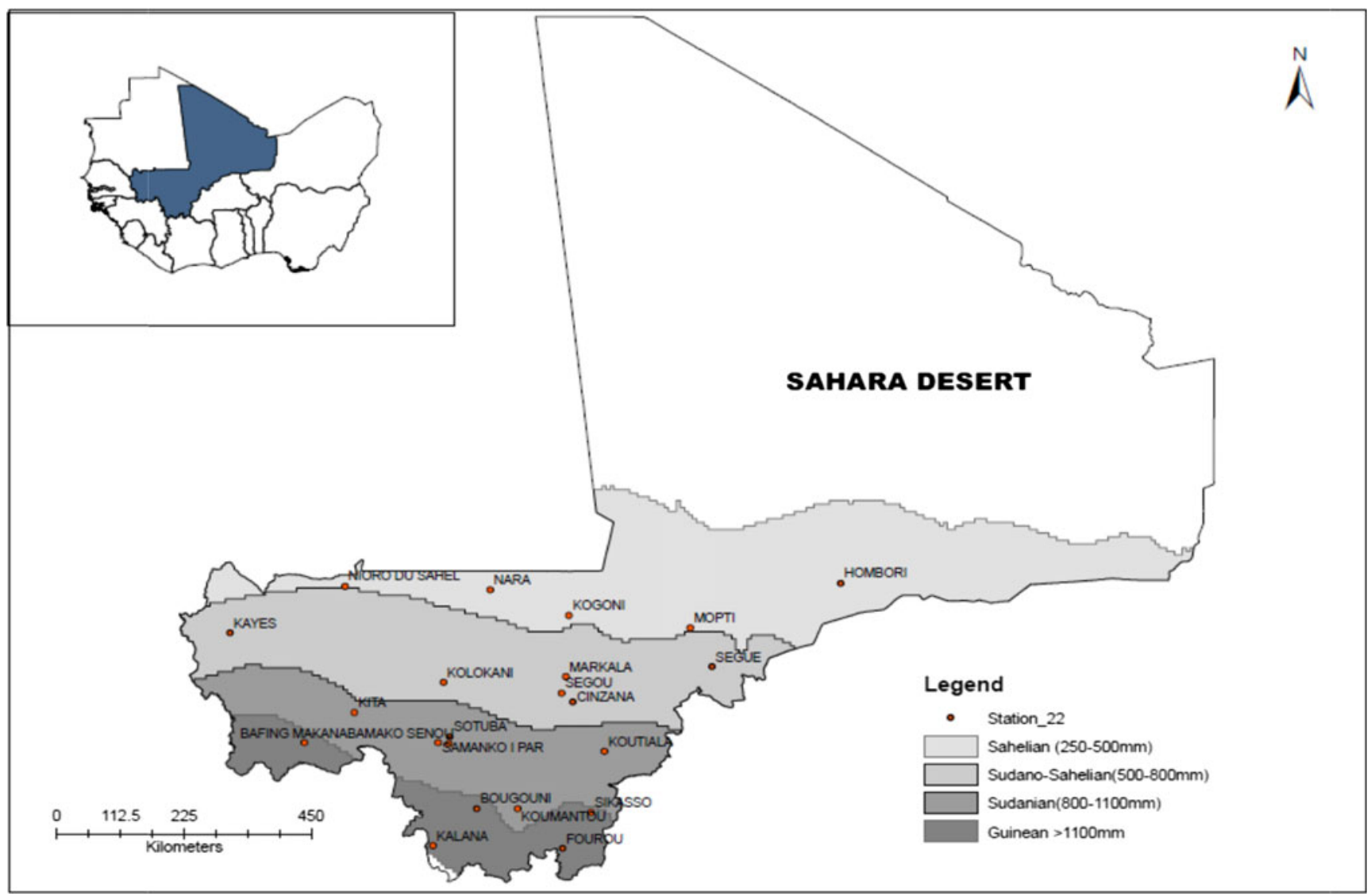

Fig. 1 Map of Mali showing the selected rainfall stations and agroecological zones

highest value in Sahelian zone that indicates a more pronounced inter-annual variability (e.g. Nioro du Sahel estimated about $30 \% \mathrm{CV}$ ). These results confirmed by McSweeney et al. (2010) and Callo-Concha et al. (2013) that reported the seasonal rainfall across AEZ of Mali are driven by the movement of the tropical rain belt (also known as the inter-tropical convergence zone, ITCZ) and strongly influenced by the West African monsoon. The ITCZ oscillates between the southern tropics and northern over the course of a year, and its movement commences rainfall in the southern region progresses towards the north between June and October. It reaches a peak in August, and the amount diminishes rapidly with increasing latitude. Thus, variations in the latitudinal movements of the ITCZ from one year to year causes large inter-annual variability in wet-season rainfall, which makes the region suffer reoccurring drought.

\subsection{Approaches tested}

Many studies have proposed method for determining the date of ORS which coincides with the date of OGS in West Africa. This ranges from the traditional to semi-empirical and scientific techniques, using monthly, decadal or the determination of the length of dryspells, daily rainfall (e.g. Ati 1996). In this present study, the question is 'which onset of rain definition is most suitable to define the start of growing season and fitted into farmer's planting time, for few selected cereal crops (Maize, Sorghum and Millet) across AEZ of Mali'? The following onset definitions are considered;

Def_1 Defined the onset date as the date after 1 May when rainfall accumulated over three consecutive days was at least $20 \mathrm{~mm}$ and when no dryspell within the next 30 days exceeded 7 days (Sivakumar 1988).

Def 2 Defined onset of rain as a receiving total of $30 \mathrm{~mm}$ within 10 days, after which there is no dryspell longer than seven (7) days within the next 30 days (Kasei and Afuakwa 1991)

Def 3 Defined as a total rainfall of at least $20 \mathrm{~mm}$ at least two rainy days in a 7-day period followed by $2-$ 3 weeks, each with at least $50 \%$ of the local crop water requirement (Omotosho et al. 2000). This definition was modified to fit in into the model used as the start of the first two rains totalling $20 \mathrm{~mm}$ or more within 7 days with at least two rainy days, and no dryspell within the next 21 days exceeded 7 days.

Def 4 Defined as the first occasion after May 1 that the 10day total exceeds half the evaporation assuming a daily evaporation of $5 \mathrm{~mm}$ (FAO 1978). 
Table 1 Selected stations, their geographical coordinates and rainfall statistics

\begin{tabular}{|c|c|c|c|c|c|}
\hline Station & Lat/long & Period & Mean rainfall & SD & $\mathrm{CV}(\%)$ \\
\hline Hombori & $12.63^{\circ} \mathrm{N} / 8.02^{\circ} \mathrm{W}$ & $1950-2006$ & 394.4 & 112.5 & 28.5 \\
\hline Mopti & $14.52^{\circ} \mathrm{N} / 4.1^{\circ} \mathrm{W}$ & $1950-2008$ & 488.8 & 125.7 & 25.7 \\
\hline Kogoni & $14.73^{\circ} \mathrm{N} / 6.03^{\circ} \mathrm{W}$ & $1950-2003$ & 506.2 & 131.4 & 26.0 \\
\hline Nioro du Sahel & $15.23^{\circ} \mathrm{N} / 9.60^{\circ} \mathrm{W}$ & $1950-2006$ & 503.4 & 151.4 & 30.1 \\
\hline Nara & $15.16^{\circ} \mathrm{N} / 7.28^{\circ} \mathrm{W}$ & $1950-2010$ & 426.4 & 98.6 & 23.1 \\
\hline Segue & $13.85^{\circ} \mathrm{N} / 3.75^{\circ} \mathrm{W}$ & $1950-2008$ & 589.2 & 131.8 & 22.4 \\
\hline Kolokani & $13.58^{\circ} \mathrm{N} / 8.03^{\circ} \mathrm{W}$ & $1950-2006$ & 733.4 & 167.0 & 22.8 \\
\hline Kayes & $14.43^{\circ} \mathrm{N} / 11.43^{\circ} \mathrm{W}$ & $1950-2007$ & 651.4 & 144.0 & 22.1 \\
\hline Markala & $13.68^{\circ} \mathrm{N} / 6.08^{\circ} \mathrm{W}$ & $1950-2004$ & 578.0 & 146.4 & 25.3 \\
\hline Segou & $13.4^{\circ} \mathrm{N} / 6.15^{\circ} \mathrm{W}$ & $1950-2010$ & 661.3 & 135.4 & 20.5 \\
\hline Cinzana & $13.25^{\circ} \mathrm{N} / 5.97^{\circ} \mathrm{W}$ & $1961-2010$ & 697.4 & 128.5 & 18.4 \\
\hline Samanko I Par & $12.52^{\circ} \mathrm{N} / 8.07^{\circ} \mathrm{W}$ & $1968-2010$ & 933.1 & 147.9 & 15.9 \\
\hline Sotuba & $12.656^{\circ} \mathrm{N} / 7.93^{\circ} \mathrm{W}$ & $1950-2010$ & 948.8 & 181.9 & 19.2 \\
\hline Bamako-Senou & $12.53^{\circ} \mathrm{N} / 7.97^{\circ} \mathrm{W}$ & $1980-2010$ & 619.6 & 135.6 & 21.9 \\
\hline Koumatou & $11.42^{\circ} \mathrm{N} / 6.85^{\circ} \mathrm{W}$ & 1960-1998 & 996.6 & 209.1 & 20.4 \\
\hline Kita & $13.07^{\circ} \mathrm{N} / 9.45^{\circ} \mathrm{W}$ & $1950-2008$ & 970.0 & 212.2 & 21.9 \\
\hline Koutiala & $12.4^{\circ} \mathrm{N} / 5.47^{\circ} \mathrm{W}$ & $1950-2008$ & 923.1 & 193.4 & 21.0 \\
\hline Bafing-Makana & $12.55^{\circ} \mathrm{N} / 10.25^{\circ} \mathrm{W}$ & $1950-2000$ & 1054.9 & 214.0 & 20.3 \\
\hline Fourou & $10.73^{\circ} \mathrm{N} / 6.13^{\circ} \mathrm{W}$ & $1950-2010$ & 1162.9 & 209.8 & 18.0 \\
\hline Kalana & $10.78^{\circ} \mathrm{N} / 8.2^{\circ} \mathrm{W}$ & $1950-2000$ & 1370.0 & 298.3 & 21.8 \\
\hline Bougouni & $11.41^{\circ} \mathrm{N} / 7.5^{\circ} \mathrm{W}$ & $1950-2010$ & 1162.9 & 209.8 & 18.0 \\
\hline Sikasso & $11.35^{\circ} \mathrm{N} / 5.68^{\circ} \mathrm{W}$ & 1950-2010 & 1170.1 & 194.6 & 16.6 \\
\hline
\end{tabular}

$S D$ standard deviation, $C V$ coefficient of variation

Cessation of the growing period (CGS) defined after Maikano (2006) as a date after September 1st when the soil water content down to $60-\mathrm{cm}$ depth is nil with a daily potential evapotranspiration of $5 \mathrm{~mm}$. To consider the latter rains, useful for crops production, in the calculation of CGS, the soil water holding capacity was set to $100 \mathrm{~mm}$ (Traoré et al. 2000) rather than $60 \mathrm{~mm}$ proposed by Maikano (2006). Then, length of growing season (LGS) was estimated by subtracting OGS from CGS. The analysis was performed with the model INSTAT developed by Stern et al. (2006) which allow climatic event study. In the model, we defined the rainy day as a day with rainfall amount of $0.85 \mathrm{~mm}$, because this value is used as minimum observing standard in the National Meteorological office. For uniformity purposes, all the methods were set to define onset date from May 1 . This principle is based on the quantity and distribution of rainfall for the region (Omotosho 1992).

\subsection{Planting dates definition}

Due to lack of availability of historical data on planting date either through farmers or research institutions to validate each estimated onset date, expert knowledge on farmer's sowing dates was collected to discretize the sowing window into seven (7) planting dekads (Fig. 2) roughly spreading across the crops (maize, millet and sorghum). The sowing date varied between days of years 170 and 206 at Sahelian zone, 160 to 196 at Sudano-Sahelian zone, 148 to 192 at Sudanian zone and 120 to 192 at Guinea Savanna zone, respectively. The probability of a farmer's planting during any one of the seven dekads follows a normal distribution (Fig. 2). The estimated mean onset date from each method was statistically compared with the farmer's planting date according to each crop across the AEZ. The hypothesis also includes a time lag minimum of 7 days between the mean onset date and farmers' sowing dates for the crops. This period is to account for land preparation prior planting.

\subsection{Data analysis}

A simple model of probability distribution was used to analyse the most preferred method to define OGS based on early, normal and late dates respectively according to the selected stations in each ecological zone: the early onset date (indicated as 5-year return periods), normal onset date (indicated as 2year return periods) and late onset date (indicated as 5-year return periods), respectively. Using a simple model probability distribution chart, we estimated mean seasonal length, the chance of having two thirds $(2 / 3)$ of the season length and $95 \%$ probability significant level for most years across the 
(a) Sahelian

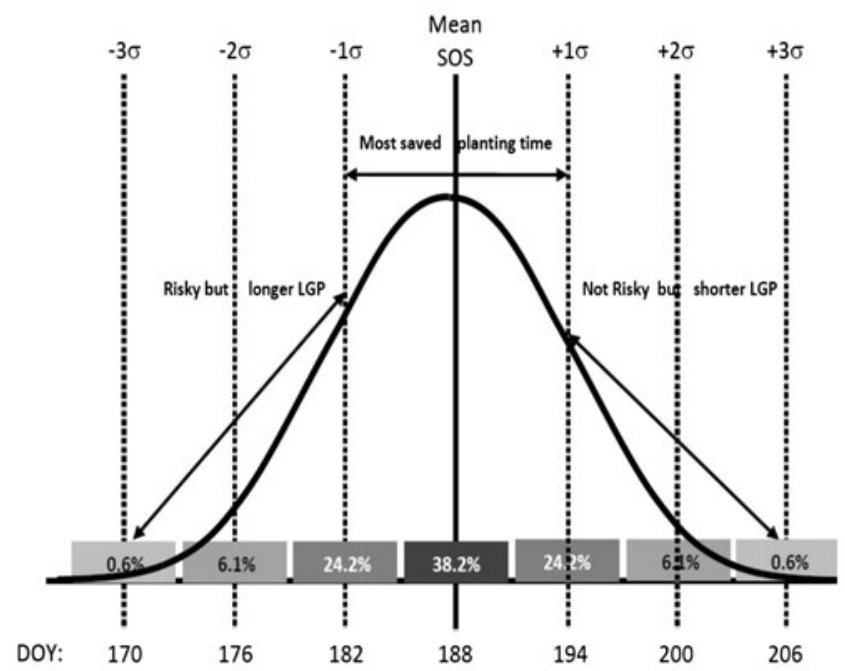

(c) Sudanian

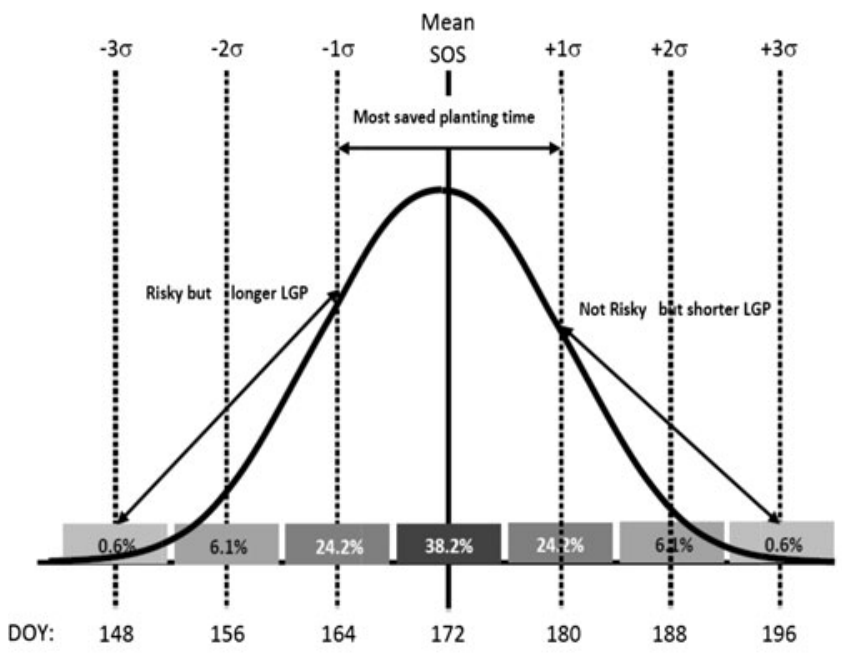

(b) Sudano-sahelian

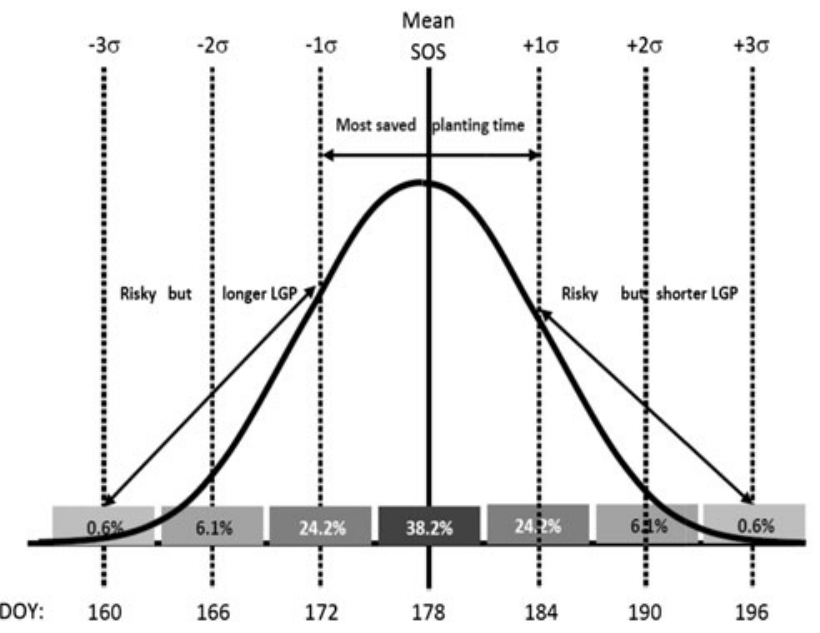

(d) Guinea savannah

Fig. 2 a-d Discretized probabilities of farmer planting time taking place within the sowing window in each the ecological zone based on the expert knowledge information

agroecological zones. In addition to the estimates, the duration to maturity for few selected varieties of the study crops (Table 2) was used to compare with the outcome.

\section{Results and discussions}

\subsection{Comparative analysis of individual method with farmers planting window}

A normal probability distribution for farmer's sowing window (Fig. 2) compared the estimated mean onset dates of rainfall (Table 3) to determine OGS according to the crops selected for the each zone. The approach evaluated the appropriateness of the individual method to determine the definition of onset of

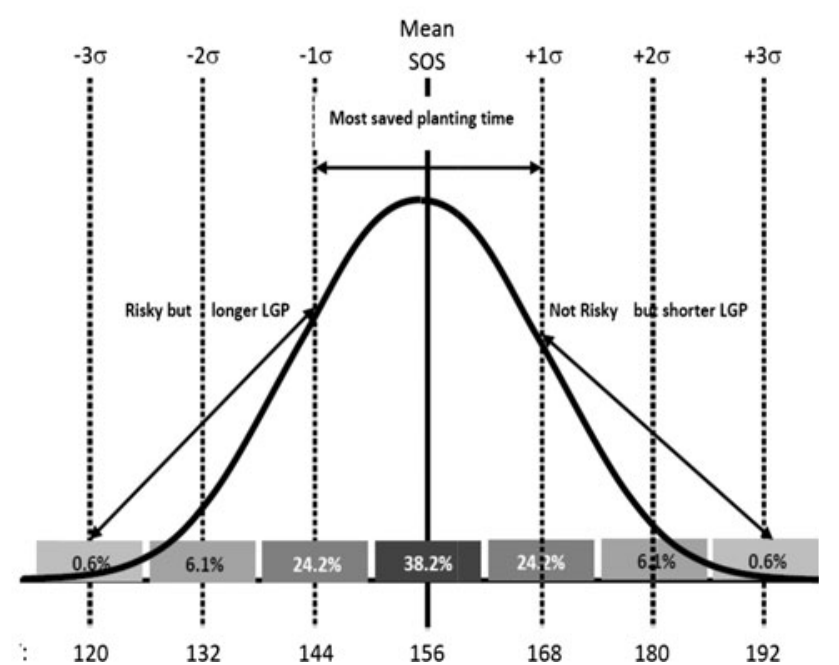


Table 2 Characteristics of the most cultivated crop varieties within the West Africa semi-arid tropics

\begin{tabular}{llllll}
\hline Crop type & Local name & Selected name & Breeder & Variety maturity & Duration from planting to maturity(days \\
\hline \multirow{2}{*}{ Maize } & Zangueréni & Zangueréni & IER & Early & $80-90$ \\
& Dembagnuman & Obatanpa & CIMMYT/CRI & Medium & $105-110$ \\
& Sotubaka & Suwan 1-SR & CIMMYT/IITA & Late & $110-120$ \\
\multirow{3}{*}{ Millet } & Sossat & Sossat c-88 & ICRISAT/IER & Early & 90 \\
& Toroniou & Toroniou & IER & Medium & $100-110$ \\
& M9D3 & M9D3 & IER & Late & $125-130$ \\
\multirow{2}{*}{ Sorghum } & Jakumbe & CSM63E & IER & Early & 100 \\
& Jigui Seme & CSM388 & IER & Medium & 125 \\
& Soumalemba & IS15-401 & CIRAD/ICRISAT & Late & 145 \\
\hline
\end{tabular}

Source: FAO (2008)

hypothesis based on a time lag minimum of 7 days between the mean onset date and traditional farmers' sowing date for the crops, we found Def 4 most suitable compared to the mean onset OGS estimated from Def_1 to Def 3 that indicated too late dates in the Sahelian and Sudano-Sahelian zones. We observed failure of the methods to yield appropriate OGS date in some years based on the dry spell prevailing condition in the AEZ which leads to shortening of length of growing season. It implies that no successful planting of these crops can take place

However, the results were opposite in the case of Sudanian and Guinea Savanna zones when the estimated mean OGS were compared with the farmer average planting time for the crops (maize, millet and sorghum). In Sudanian zones, Def_1 to Def_3 estimated mean onset dates as 159 (Jun 08) \pm 14 days, 159 (Jun 08) \pm 13 days and 161 (Jun 10) \pm 14 , respectively, while Def 4 estimated mean onset date of 144 (May 24) \pm 13 days. In Guinea Savanna, Def_1 to Def_3 estimated mean onset dates was 147 (May 27), 146 (May 26) and 145 (May 24) with a standard deviation range from 13 to 15 days, while the Def_4 estimated mean date was 133 (May 13) and standard deviation of \pm 9 days. From these results coupled with the criteria setup for the evaluation, Def_3 was found suitable for estimation of OGS over Sudanian zone and Guinea Savanna zones compared to other methods as depicted in Table 2. Apart from Def_3 which was consistent with the shortest time lag for farmer's land preparation period and the satisfaction of $50 \%$ crop water requirement, the sowing dates will ensure

Table 3 Comparison of mean onset dates from each method with the farmer's average planting time for maize, sorghum and millet

\begin{tabular}{|c|c|c|c|c|c|c|c|c|}
\hline AEZ & Hypothesis & Def_1 & Def_2 & Def_3 & Def_4 & Maize & Sorghum & Millet \\
\hline \multirow[t]{4}{*}{ Sahelian } & Mean onset & 193 & 191 & 193 & 173 & 194 (Jul 13 ) & 188 (Jul 07) & 188 (Jul 07) \\
\hline & St. dev & 15 & 14 & 14 & 15 & 6 & 6 & 6 \\
\hline & Time lag & -5 & -3 & -5 & 15 & & & \\
\hline & Mean LGS & 70 & 72 & 70 & 90 & & & \\
\hline \multirow[t]{4}{*}{ Sudano-Sahelian } & Mean onset & 179 & 177 & 178 & 158 & 174 (Jun 23) & 178 (Jun 27) & 178 (Jun 27 \\
\hline & St. dev & 15 & 16 & 17 & 16 & 6 & 6 & 6 \\
\hline & Time lag & -3 & -1 & -2 & 19 & & & \\
\hline & Mean LGS & 101 & 103 & 102 & 123 & & & \\
\hline \multirow[t]{4}{*}{ Sudanian } & Mean onset & 160 & 159 & 162 & 144 & $172($ Jun 21) & 177 (Jun 26 ) & 177 (Jun 26) \\
\hline & St. dev & 14 & 13 & 14 & 13 & 8 & 8 & 8 \\
\hline & Time lag & 12 & 13 & 10 & 28 & & & \\
\hline & Mean LGS & 132 & 133 & 131 & 149 & & & \\
\hline \multirow[t]{4}{*}{ Guinea Savanna } & Mean onset & 147 & 146 & 145 & 133 & 156 (Jun 05) & 156 (Jun 05) & 156 (Jun 05) \\
\hline & St. dev & 15 & 15 & 13 & 9 & 12 & 12 & 12 \\
\hline & Time lag & 9 & 10 & 11 & 23 & & & \\
\hline & Mean LGS & 151 & 152 & 154 & 165 & & & \\
\hline
\end{tabular}

The bold part indicates the most suitable method found closed to the criteria used. Mean onset (in Julian days)

St. dev standard deviation (in \pm days), Time lag difference between farmer's average planting time and mean onset date (in days), $L G S$ average length of growing season (in days) 
Fig. 3 a-d Onset dates of growing season (in Julian days) by each method (average of all stations in each AEZ)

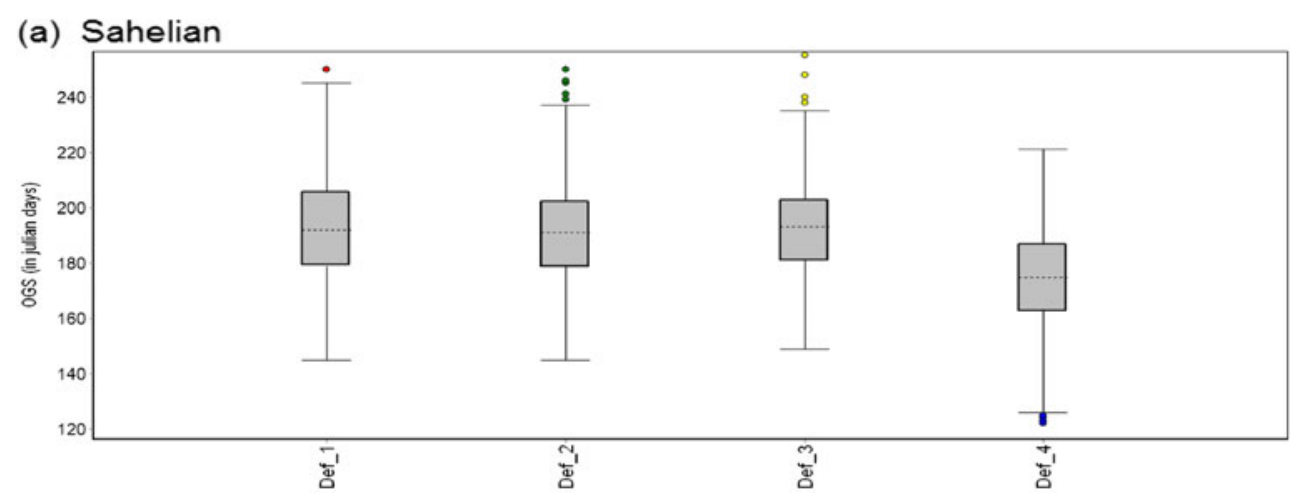

(b) Sudano-sahelian

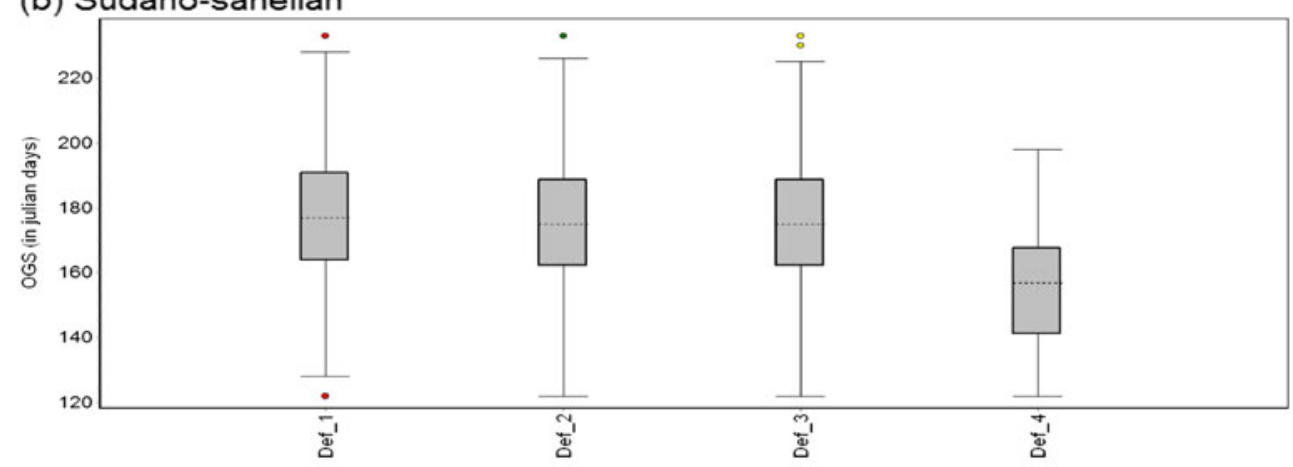

(c) Sudanian

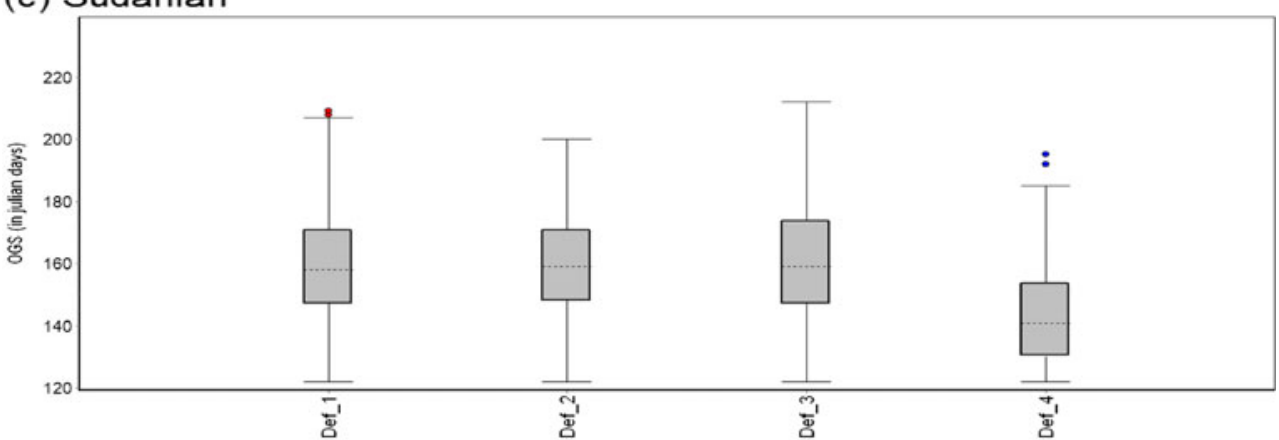

(d) Guinea Savanna

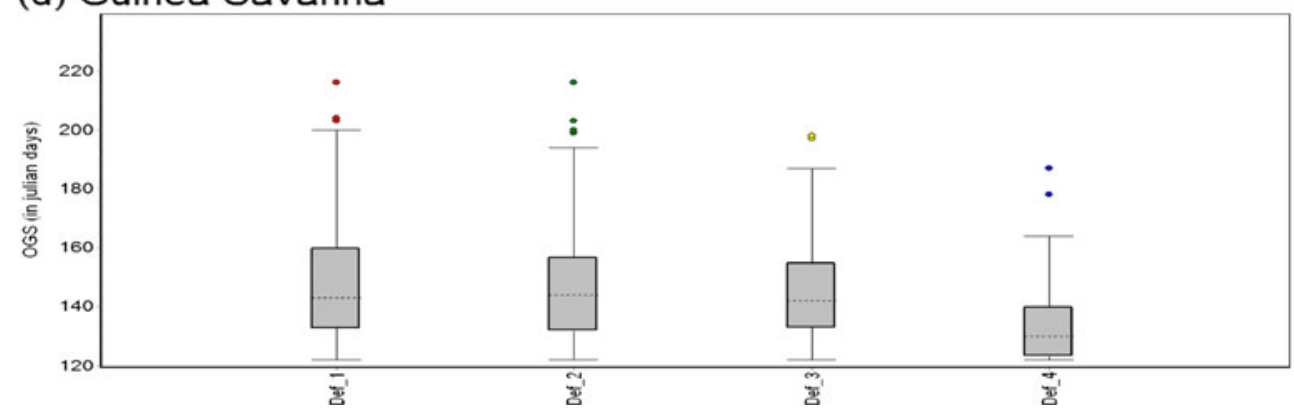

high crop yields and hence, successful farming activities. Based on the most suitable method, the early, normal and late onset dates of growing season are Def 4 for Sahelian and Sudano-Sahelian, while Sudanian and Guinea Savanna used Def_3 accordingly. In this study, the results of the appropriate methods adopted to evaluate onset date of growing season were similar to the fuzzy logic approach adopted over Volta
Basin in Ghana by Laux et al. (2010) and discriminant functions proposed across climatic zones of Burkina Faso by Lodoun et al. (2013). However, the approach adopted in this study is not meant to replace existing ones in the Sahel region (e.g. Omotosho 1992; Sivakumar 1988, 1993) but to help farmers make decision at the farm scale based on the choice of crop species. 
Furthermore, the estimated early, normal and late onset dates of growing season from the most suitable method across the AEZ were based on a simple model normal probability distribution (Table 4). Across the stations considered in the Sahelian zone estimates the early onset date between Julian days 137 (May 17) and 160 (Jun 09) with a standard error of \pm 4 days, normal onset date occurred from days 165 (Jul 14) to 178 (Jun 27) with a standard error of \pm 3 days, while the late onset date occurred in the second and third week of July (from Julian days 190 (Jul 09) to 200 (Jul 19); these values were associated with $95 \%$ confidence interval respectively. In Sudano-Sahelian zone, the estimated early onset date occurred in the first and third week in May, varied from Julian days 121 (May 01) to 138 (May 18) with the standard error of \pm 3 days. Normal onset date occurred between Julian days 147 (May 27) and 167 (Jun 16), with a standard error of estimate of \pm 3 days, while the late onset date occurred from Julian days 160 (Jun 09) to 169 (Jun 18).

In Sudanian zone, the result indicated that the early onset date was Julian days 139 (May 19) to 163 (Jun 12) with an estimated standard error of \pm 3 days. Normal onset date varied from days 153 (Jun 02) to 173 (Jun 22), while the late onset date which occurred in the third week of June to 2nd of July varied from day 168s (Jun 17) to 192 (Jul 11) with $95 \%$ confidence intervals for the estimate. Similarly, in Guinea Savanna zone, the second week of May was estimated for early onset date, fourth week of May for normal and late onset dates on second week in June respectively with the exception of Bafing-Makana. This station is located in the northern Guinea Savanna zone region which is close to Sudanian ecological zone. From the above results, it shows that the OGS progresses northwards following prediction. The early onset date that started in southern semi-arid in Guinea Savanna zone by early May progressed northwards and remained wide spread between third and fourth week of May at Sudanian zones. In the month of June, early onset date occurred between 2 nd and 20th June and covered Sudano-Sahelian and Sahelian zone as estimated. The above estimates were in agreement with the report of McSweeney et al. (2010) that the earliest onset of the rains commences in May over southern Sahel and progressed to the northern Sahel in June.

\subsection{Estimating length of growing season across the ecological zones}

Figure 4 presented the estimated length of growing season across the ecological zones relative to the difference between most suitable onset method for each AEZ and the estimated

Table 4 Estimated onset dates based on the simple model normal probability distribution

\begin{tabular}{|c|c|c|c|c|c|c|}
\hline Station & Early onset & $95 \%$ confidence interval & Normal onset & $95 \%$ confidence interval & Late onset & $95 \%$ confidence interval \\
\hline Hombori & 04 Jun & 28 May-10 Jun & 22 Jun & 16 Jun-28 Jun & $10 \mathrm{Jul}$ & 04 Jul-17 Jul \\
\hline Mopti & 20 May & 10 May-May 28 & 14 Jun & 06 Jun-21 Jun & $09 \mathrm{Jul}$ & 01 Jul-19 Jul \\
\hline Kogoni & 17 May & 04 May-28 May & 18 Jun & 07 Jun-28 Jun & $19 \mathrm{Jul}$ & 09 Jul-25 Jul \\
\hline Nioro du Sahel & 09 Jun & 03 Jun-13 Jun & 27 Jun & 19 Jun-29 Jun & $09 \mathrm{Jul}$ & 04 Jul-15 Jul \\
\hline Nara & 09 Jun & 03 Jun-14 Jun & 25 Jun & 20 Jun-30 Jun & $10 \mathrm{Jul}$ & 07 Jul-17 Jul \\
\hline Segue & 18 May & 11 May -23 May & 02 Jun & 28 May-07 Jun & 18 Jun & 12 Jun-24 Jun \\
\hline Kolokani & 17 May & 11 May -21 May & 01 Jun & 26 May-04 Jun & 13 Jun & 09 Jun-19 Jun \\
\hline Kayes & 04 Jun & 31 May-08 Jun & 16 Jun & 13 Jun-19 Jun & 28 Jun & 24 Jun-03 Jul \\
\hline Markala & 09 May & 30 Apr-17 May & 02 Jun & 26 May-10 Jun & 26 Jun & 18 Jun-06 Jul \\
\hline Segou & 01 May & 28 Apr-09 May & 28 May & 20 May-05 Jun & 24 Jun & 15 Jun-05 Jul \\
\hline Cinzana & 13 May & 07 May-18 May & 27 May & 22 May-31 May & 09 Jun & 05 Jun-15 Jun \\
\hline Samanko I Par & 19 May & 12 May-24 May & 02 Jun & 28 May-08 Jun & 17 Jun & 11 Jun-23 Jun \\
\hline Sotuba & 30 May & 25 May-03 Jun & 13 Jun & 09 Jun-17 Jun & 27 Jun & 22 Jun-02 Jul \\
\hline Bamako-Senou & 12 Jun & 31 May-10 Jun & 22 Jun & 15 Jun-25 Jun & $11 \mathrm{Jul}$ & 05 Jul-16 Jul \\
\hline Koumatou & 24 May & 13 May-01 Jun & 12 Jun & 05 Jun-20 Jun & 02 Jul & 24 Jun-12 Jul \\
\hline Kita & 30 May & 25 May-02 Jun & 10 Jun & 06 Jun-13 Jun & 21 Jun & 17 Jun-25 Jun \\
\hline Koutiala & 22 May & 16 Мay-27 May & 06 Jun & 01 Jun-11 Jun & 22 Jun & 16 Jun-27 Jun \\
\hline Bafing-Makana & 23 May & 15 Мay-28 May & 04 Jun & 30 May-09 Jun & 17 Jun & 11 Jun-24 Jun \\
\hline Fourou & 11 May & 05 Мay-16 May & 26 May & 21 May-30 May & 09 Jun & 05 Jun-15 Jun \\
\hline Kalana & 09 May & 01 May-15 May & 27 May & 21 May-01 Jun & 13 Jun & 07 Jun-21 Jun \\
\hline Bougouni & 11 May & 05 Мay-16 May & 26 May & 21 Мay-30 May & 09 Jun & 05 Jun-15 Jun \\
\hline Sikasso & 09 May & 03 Мay-14 May & 24 May & 19 May-29 May & 09 Jun & 04 Jun-15 Jun \\
\hline
\end{tabular}

Significant $(P<0.05)$. Standard error of the estimates varied from \pm 2 to \pm 5 among stations considered. Early onset date indicates 5 -year return periods. Normal onset dates indicates 2 -year return periods. Late onset date indicates 5 -year return periods 
Fig. 4 a Sahelian, b SudanoSahelian, c Sudanian, and d Guinea Savanna zone: probability distribution length of growing season (in days) based on the most suitable OGS relative to farmer's sowing window

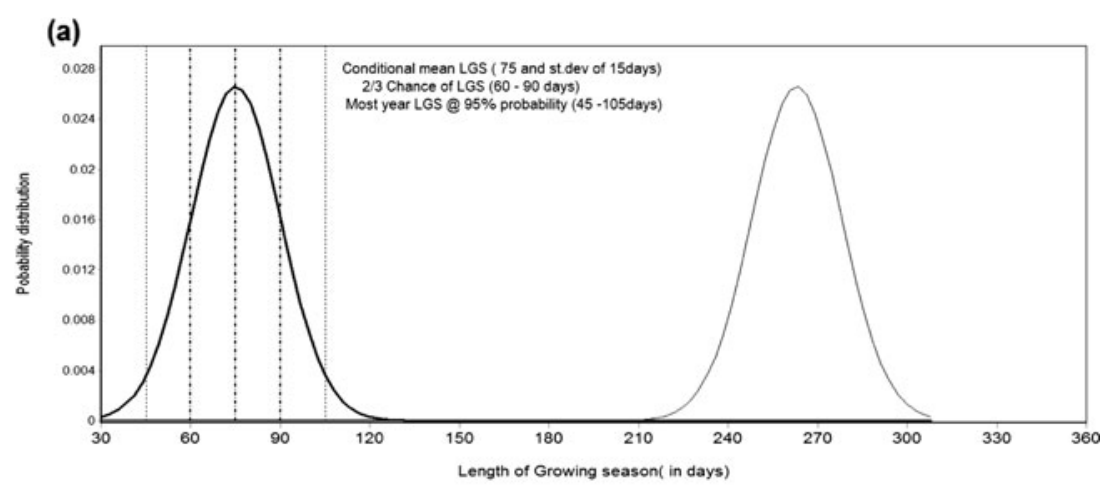

(b)

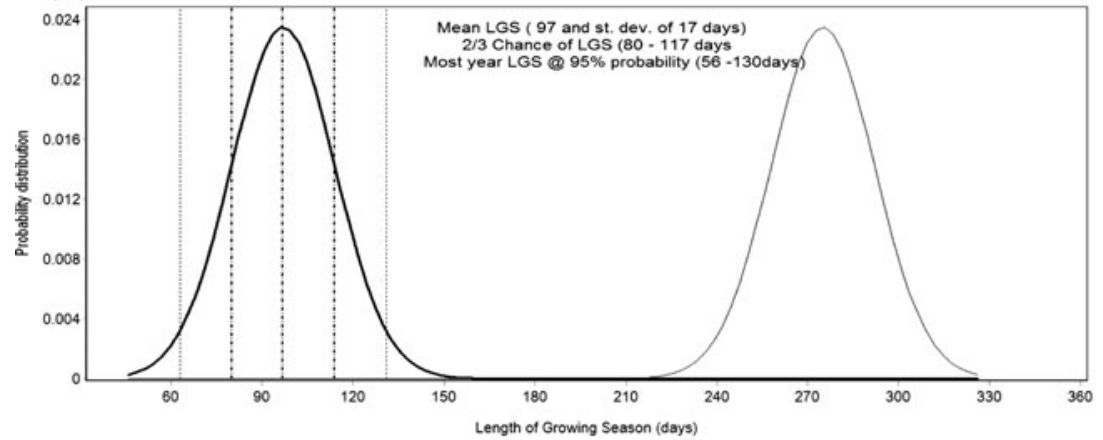

(c)

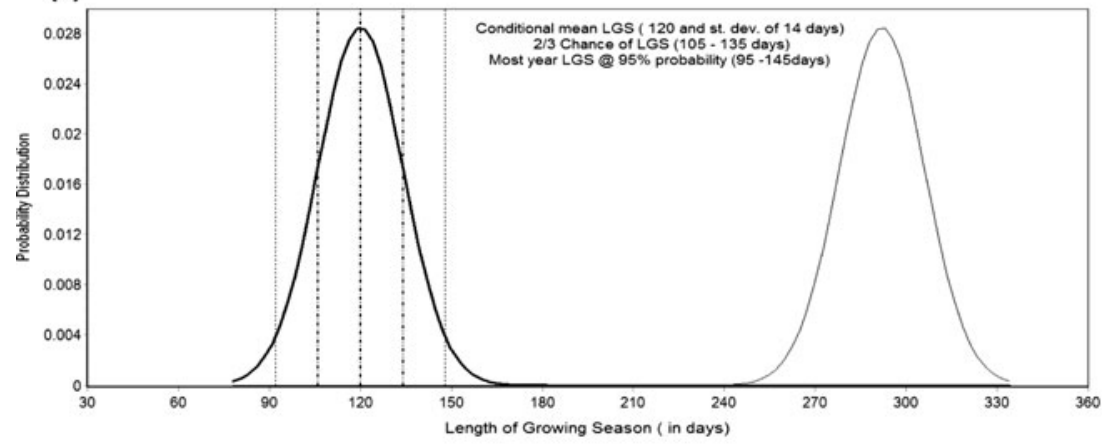

(d)

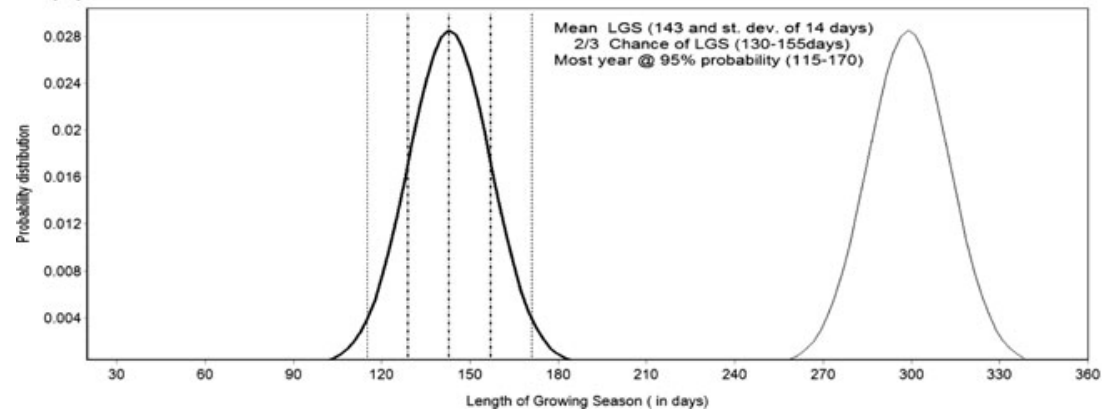

mean cessation date of growing season (CGS). The results show a northwards decrease in length of growing season (LGS). In Sahelian zone, the average LGS was estimated at 75 days with \pm 15 days as a standard deviation; in addition, the chance of farmers having two thirds (2/3) of LGS varied between 60 and 90 days, and most year (estimated at $95 \%$ probability) LGS varied between 45 and 105 days. In the case of Sudano-Sahelian zone, the average LGS was estimated at 97 days with \pm 17 days as a standard deviation, and the chance of farmers having two thirds (2/3) of LGS varied between 80 and 117 days and most year (estimated at $95 \%$ probability) LGS varied between 65 and 130 days. For Sudanian zone, mean season length was 120 days, \pm 14 days as standard deviation, the chance of farmer having two thirds (2/3) of LGS 
varied between 105 and 135 days, and most year (estimated at $95 \%$ probability) LGS varied between 95 and 145 days. Guinea Savanna zone had the longest estimated days of LGS at 143 days, \pm 14 days as the standard deviation. A two thirds $(2 / 3)$ chance of season length ranged from 130 to 155 days, and the estimated $95 \%$ probability for most years varied between 115 and 170 days.

However, in order to establish the impacts of these estimates on the selected crops, we evaluated the estimates with duration to maturity of some varieties for the crops (Table 2). It implies that only early maturing cultivars of these crops can be grown in Sahelian zone and early and medium maturity varieties are possible over Sudano-Sahelian zones, while Sudanian and Guinea Savanna have greater opportunity for cultivation any of these crops genotypes up to 4 months during the growing season. Also, there was less variability $(<7 \%$ $\mathrm{CV}$ ) in the cessation of rainy season across the agroecological zones either for early or late onset date of growing season. It however implies that year with early OGS will lead to longer LGS and vice versa. The results agreed with the study of Sivakumar (1988) over southern Sahelian and Sudanian zones of Niger and Burkina Faso. It therefore implies that farmers in the region should base farming activities on estimated mean seasonal length or two thirds chance of seasonal length and choose varieties that complete their growing cycle within short period to prevent low crop yield. These results are consistent with those of Dingkuhn et al. (2003) who reported that low crop yields from sorghum and millet can be minimized if farmer's used varieties that can attain flowering at least 1520 days prior to the end of growing season drought. This condition is very critical to Sahelian and Sudano-Sahelian zones, but Sudanian and Guinea Savanna zone late maturity cereal varieties can complete their life cycle.

\section{Conclusions}

Analysis of long-term daily rainfall was applied to evaluate four (4) known definitions of onset of rainfall and one (1) definition of cessation of rain, and in comparison with farmer's sowing window for major cereals crops (maize, millet and sorghum) in the semi-arid part of Mali. The study established the most reliable and suitable method for determining the onset of growing season (OGS) as well as the length of growing season (LGS) in the various Malian agroecological zones (and crops). The methods tested that showed a strong relationship between the onset and length of growing season across the selected stations are consistent with previous studies. A significant addition of this study to the literature is that the applied statistical analysis compared these methods with farmers planting window for the most cultivated cereal crops as well as to their maturity dates. The results indicated that the most suitable methods selected would prevent the false start or too late onset date of growing season across the AEZ. The study observed that Def 4 is the most appropriate in the Sahelian and Sudano-Sahelian zones, while Def_3 was found suitable for Sudanian and Guinea Savanna zones. The results from this study negate the use of one method for prediction of OGS across the whole West African region as reported by many studies (e.g. Lodoun et al. (2013) but supported the recent fuzzy logic approach over Volta Basin by Laux et al. (2010). Furthermore, with the LGS based on the difference between the most suitable OGS estimates and cessation of growing season (CGS) across the AEZ, it is confirmed that the current LGS over Sahelian zone may not be suitable for growing medium and late maturity varieties of the cereal crops considered. Also, only early and medium maturity variety is possible over Sudano-Sahelian zones. While the estimated longer duration of growing season averages of 120 and 143 days with \pm 14 days, standard deviation over Sudanian and Guinea Savanna zones suggests maturity of these cereal crops successfully. Based on the results of this study, it is recommended that further evaluation of estimates can be experimented via participatory approach with farmers, agrometeorologists and agriculture extension officers, for predicting the onset dates 'on-line' for dissemination to farmers. It would ensure proper decision making on sowing dates, and the appropriate crop species and varieties to be cultivated for each location across the ecological zones. The findings would also be a useful input in the development of weather-responsive crop management packages and guidelines across Mali agroecologies.

Acknowledgments This work was funded by the Federal Ministry of Education and Research (BMBF) through the West African Service Centre on Climate Change and Adapted Land Use (WASCAL), Graduate Research Program (GRP). Financial support is gratefully acknowledged.

\section{References}

Ati FO (1996) A comparison of methods to detect the onset of the growing season and its trends for some stations in the Sudan Savannah of Northern Nigeria M.Sc. thesis, Department of Geography, Ahmadu Bello University, Zaria, Nigeria

Ati OF, Stigter CJ, Oladipo EO (2002) A comparison of methods to determine the onset of the growing season in Northern Nigeria. Int J Climatol 22:731-742

Callo-Concha D, Gaiser T, Webber H, Tischbein B, Müller M, Ewert F (2013) Farming in the West African Sudan Savanna: insights in the context of climate change. Afr J Agric Res 8(38):4693-4705. doi: 10.5897/AJAR2013.7153

D i a 11 o M A ( $\left.\begin{array}{llll}2 & 0 & 0 & 1\end{array}\right) \quad$ M i s e e n p 1 a c e d e procéduresd'analysesstatistiquesagroclimatiqueset labanque de donnéessur les paramètres de la saisonagricolepluviale. Centre Régional AGRHYMET, Niamey

Dingkuhn M, Baron C, Bonnal V, Maraux F, Sarr B, Sultan B, Clopes A, Forest F, (2003) Decision support tools for rainfed crops in the Sahel at the plot and regional scales. In: StruifBontkes TE, Wopereis MCS (eds) Decision Support Tools for Smallholder Agriculture in Sub- 
Saharan Africa - A practical Guide, CTA Wageningen, The Netherlands, pp 127-139

FAO (1978) Report on the agro-ecological zones projects, vol. 1. Methodology and results for Africa. FAO, Rome

FAO (2008) West African catalogue of plant species and varieties. Food and Agriculture Organization of the United Nations, Rome, pp 285289

Graef F, Haigis J (2001) Spatial and temporal rainfall variability in the Sahel and its effects on farmers' management strategies. J Arid Environ 48:221-231

Kasei CN, Afuakwa JJ (1991) Determination of optimum planting date and growing season of maize in the northern savanna zone of Ghana. In: Sivakumar MVK, Wallace JS, Renard C, Giroux C (eds) Soil Water Balance in the Sudan Sahelian Zone. IAHS Publication, No. 199. International Association of Hydrological Sciences, Wallingford

Laux P, Kunstmanna H, Bardossy A (2008) Predicting the regional onset of the rainy season in West Africa. Int $\mathrm{J}$ Climatol 28:329-342

Laux P, Wagner S, Wagner A, Bárdossy A, Jacobeit J, Kunstmann H (2009) Modelling daily precipitation features in the Volta basin of West Africa. Int J Climatol 29(7):937-954. doi:10.1002/joc.1852

Laux P, Jäckel G, Munang R-T, Kunstmann H (2010) Impact of climate change on agricultural productivity under rainfed conditions in Cameroon - a method to improve attainable crop yields by planting date adaptations. Agric For Meteorol 150:1258-1271. doi:10.1016/ j.agrformet.2010.05.008

Lodoun T, Sanon M, Giannini A, Traoré PS, Somé L, Rasolodimby JM (2013) Seasonal forecasts in the Sahel region: the use of rainfallbased predictive variables. Theor Appl Climatol. doi:10.1007/ s00704-013-1002-1

Maikano I (2006) Generate prototype WCA recommendation maps for selected sorghum (8) and millet (8) cultivars based on updated endof season dates(PRODEPAM, activity). Raport de stage. Institut International de Recherche sur les Cultures des zones tropicales semi arides (ICRISAT-Bamako)

McSweeney C, New M, Lizcano G (2010) UNDP climate change country profiles: Afghanistan. Available: http://country-profiles.geog.ox.ac. uk. Accessed 10 May 2013
Mishra A, Hansen JW, Dingkuhn M, Baron C, Traore SB, Ndiaye O, Ward MN (2008) Sorghum yield prediction from seasonal rainfall forecasts in Burkina Faso. Agric For Meteorol 148(11):1798-1814

Odekunle TO (2004) Determining rainfall onset and retreat dates in Nigeria. J Hum Ecol 16(4):239-247

Omotosho JB (1992) Long-range prediction of the onset and end of the rainy season in the West African Sahel. Int J Climatol $12: 369-382$

Omotosho JB, Balogun AA, Ogunjobi K (2000) Predicting monthly and seasonal rainfall, onset and cessation of the rainy season in West Africa using only surface data. Int J Climatol 20:865-880

Rosegrant MW, Cai X, Cline SA (2002) The role of rain-fed agriculture in the future of global food production. IFPRI, Environment and Production Technology Division Discussion Paper No. 90

Sivakumar MVK (1988) Predicting rainy season potential from the onset of rains in southern sahelian and sudanian climatic zones of West Africa. Agric For Meteorol 42:295-305

Sivakumar MVK, Maidoukia A, Stern RD (1993) Agroclimatology of West Africa: Niger. Information Bulletin no 5. Patancheru, A.P. 502 324, India: Int'l Crops Research Institute for the Semi-Arid Tropics, and Niamey: Direction de la meteorology nationale du Niger, 116p

Stern RD, Coe R (1982) The use of rainfall models in agricultural planning. Agric Meteorol 26(1):35-50

Stern RD, Dennett MD, Garbutt DJ (1981) The start of the rains in West Africa. J Climatol 1:59-68

Sultan B, Baron C, Dingkuhn M, Sarr B, Janicot S (2005) Agricultural impacts of large-scale variability of the West African monsoon. Agric For Meteorol 128(1-2):93-110

Traoré SB, Reynier FN, Vaskman M, Koné B, Sidibé, Yorote A, Yattara K, Kouressy M (2000) Adaptation a lasecheres se des écotypes locaux de sorgho du Mali. Sé cheresse 11:227-237. locaux de sorgho du Mali. Sécheresse 11:227-237

Usman MT, Archer E, Johnston P, Tadross M (2005) A conceptual framework for enhancing the utility of rainfall hazard forecasts for agriculture in marginal environments. Nat Hazards 34(1):111-129

Walter MW (1967) Length of the rainy season in Nigeria. Niger Geogr J $10: 123-128$ 